\title{
INVENTÁRIO DOS CORRELATORES DISJUNTIVOS DO \\ PORTUGUÊS DO BRASIL
}

\section{INVENTORY OF DISJUNCTIVE CORRELATORS IN BRAZILIAN PORTUGUESE}

Ivo Costa Rosário Universidade Federal Fluminense rosario.ivo3@gmail.com Jovana Maurício Acosta Universidade Federal Fluminense jovanamauricio@hotmail.com

\section{RESUMO:}

Este artigo apresenta um inventário dos correlatores disjuntivos da língua portuguesa do Brasil e seus contextos de uso. Alguns dos correlatores aqui apresentados não são contemplados pelas principais gramáticas do português, apesar de apresentarem produtividade. Os pressupostos teóricos da pesquisa estão calcados na Linguística Funcional Centrada no Uso. O corpus utilizado é composto por textos retirados de versões eletrônicas da Revista Veja on-line, disponíveis em http://www.veja.abril.com.br. A pesquisa demonstra que os correlatores disjuntivos em uso no português atual são os seguintes: ou...ou, seja...seja,...ora..ora, quer...quer, e nem...nem, seja..ou, quer..ou, e nem...ou.

PALAVRAS-CHAVE: correlatores disjuntivos; uso; construção.

\section{ABSTRACT:}

This article presents an inventory of disjunctive correlators of the Brazilian variety of Portuguese language and its usage contexts. Some of the correlators presented here are not covered by the main grammars of Portuguese, although they present productivity. The theoretical assumptions of the research are based on the Usaged-Based Functional Linguistics. The corpus includes texts from electronic editions of Veja online, available at http://www.veja.abril.com.br. The research demonstrates that the usual disjunctive correlators in contemporary Portuguese are the following: ou...ou, seja..seja, ora... ora, quer...quer, nem...nem, seja..ou, quer..ou, nет...ou.

KEYWORDS: disjunctive correlators; usage; construction. 


\section{Considerações iniciais}

Normalmente, apenas a subordinação e a coordenação são apresentadas como processos de integração oracional pelas gramáticas. A correlação, por sua vez, apesar de ser preterida pela Nomenclatura Gramatical Brasileira e de contar com poucos estudos em profundidade, tem grande importância dentro dos estudos da estruturação do período e no âmbito de toda a sintaxe (cf. ROSÁRIO, 2012, 2013, 2014, 2015, 2017).

Inspirado em Câmara Jr. (1981), Rosário (2012, p. 29) cunhou uma definição para correlação, que é adotada neste trabalho: "construção sintática prototipicamente composta por duas partes interdependentes e relacionadas entre si, encabeçadas por correlatores, de tal sorte que a enunciação de uma (prótase) prepara a enunciação de outra (apódose)". Trata-se, portanto, de um arranjo sintático-semântico distinto da coordenação e da subordinação.

Em geral, no campo da alternância/disjunção, as gramáticas normativas apresentam elementos coordenativos e correlativos como se fizessem parte de um mesmo grupo. Neste trabalho, ao contrário, propomos uma distinção entre coordenação alternativa e correlação disjuntiva. A coordenação alternativa é entendida como um procedimento sintático normalmente concretizado pela conjunção coordenativa alternativa ou. A correlação disjuntiva, por sua vez, engloba correlatores ${ }^{1}$, compreendidos como articuladores sintáticos descontínuos responsáveis por veicular a correlação (ou...ou, ora...ora, etc). Feita esta importante distinção, este artigo tem como objetivo apresentar um estudo atualizado do inventário dos correlatores disjuntivos efetivamente em uso, na língua escrita sincrônica, no Português do Brasil, a partir de uma amostra de textos da mídia culta escrita.

Pautamos esta pesquisa nos pressupostos teóricos da Linguística Funcional Centrada no Uso (LFCU), nos termos de Cezario e Furtado da Cunha (2013), Traugott e Trousdale (2013), Bybee (2015), Goldberg (1995, 2006) e Oliveira e Rosário (2016). A LFCU leva em conta as inovações e as mudanças apresentadas na língua tal como efetivamente produzidas no dia a dia, ou seja, tanto as estruturas canônicas quanto as não canônicas.

Apresentamos, na seção 1, uma síntese de como a alternância/disjunção é destacada por alguns autores. Como nosso objeto de estudo é tradicionalmente conhecido como conjunção alternativa, fez-se necessário observar como alguns

O termo correlatores foi criado por Rosário (2012), em analogia com coordenadores e subordinadores. Exemplos de correlatores: não só...mas também, tanto...como, ou...ou etc. 
estudiosos tratam o assunto em questão. Na seção 2, apresentamos o referencial teórico-metodológico que ampara a pesquisa em foco: a Linguística Funcional Centrada no Uso (LFCU). Na seção seguinte, denominada Resultados, atestamos os types encontrados e a análise de dados propriamente dita. Por fim, nas considerações finais, apresentamos os contextos de uso de cada correlator disjuntivo encontrado e algumas observações adicionais de cunho mais geral.

\section{Conjunções alternativas na visão gramatical e na perspectiva dos linguistas}

Os correlatores disjuntivos, objeto deste trabalho, como citado anteriormente, são tradicionalmente conhecidos, por alguns autores, como conjunções alternativas. Vejamos, então, a partir do quadro a seguir, como algumas gramáticas apresentam as conjunções alternativas:

Quadro 1: Conjunções alternativas.

\begin{tabular}{|l|l|}
\hline $\begin{array}{l}\text { Bechara } \\
(1999, \text { p. 321) }\end{array}$ & $\begin{array}{l}\text { Enlaçam as unidades coordenadas matizando-as de um valor alternativo, } \\
\text { quer para exprimir a incompatibilidade dos conceitos envolvidos, quer para } \\
\text { exprimir a equivalência deles. Ou...ou, quer...quer, seja...seja, ora...ora }\end{array}$ \\
\hline $\begin{array}{l}\text { Rocha Lima } \\
(1999, \text { p. } 185, \\
\text { grifos nossos) }\end{array}$ & $\begin{array}{l}\text { As conjunções alternativas relacionam pensamentos que se excluem. O } \\
\text { tipo é ou, que pode repetir-se, ou não, antes de todos os elementos coorde- } \\
\text { nados: ou...ou, ora...ora, seja...seja, quer...quer, já...já. }\end{array}$ \\
\hline $\begin{array}{l}\text { Cunha e Cintra } \\
(2001, \text { p. 580, } \\
\text { grifos nossos) }\end{array}$ & $\begin{array}{l}\text { As conjunções alternativas ligam dois termos ou orações de sentido } \\
\text { distinto, indicando que, ao cumprir-se um fato, o outro não se cumpre. São } \\
\text { as conjunções ou (repetida ou não) e, quando repetidas: ora...ora, quer... } \\
\text { quer, etc. }\end{array}$ \\
\hline $\begin{array}{l}\text { Carvalho } \\
(2011, \text { p. } 365)\end{array}$ & $\begin{array}{l}\text { As conjunções alternativas justapõem pensamentos que se excluem: ou... } \\
\text { ou, já...já, quer...quer, ora...ora, seja....seja. } .\end{array}$ \\
\hline $\begin{array}{l}\text { Neves } \\
(2011, \text { p. } 593)\end{array}$ & $\begin{array}{l}\text { A conjunção coordenativa com ou marca disjunção ou alternância entre o } \\
\text { elemento coordenado no qual ocorre e o elemento anterior. }\end{array}$ \\
\hline
\end{tabular}

Verificamos, com base no quadro anterior, que algumas gramáticas referem-se às aqui chamadas correlatas disjuntivas como estruturas instanciadas por conjunções em repetição (ou conjunções duplicadas). Além disso, essas obras não fazem nenhuma referência específica à correlação, com exceção de Neves (2011), que cita a correlação com ou ao tratar da disjunção exclusiva. Deve-se destacar que Neves (2011) filia-se mais propriamente ao grupo dos linguistas, e não dos gramáticos, no sentido mais clássico do termo. 
Sob o rótulo geral de conjunções coordenativas alternativas, observamos que os autores restringem-se a citar os conectivos correlativos mais canônicos, ou seja, os que integram o padrão normativo da língua, como ou...ou, quer... quer, seja...seja, ora...ora. Curiosamente, Bechara (1999), à diferença dos outros autores aqui apresentados, não considera seja...seja, quer...quer e ora... ora como conectores. Eis uma afirmação do autor:

A numeração distributiva que matiza a ideia de alternância leva a que se empreguem neste significado advérbios como já, bem, ora (repetidos ou não) ou formas verbais imobilizadas como quer...quer, seja...seja. Tais unidades não são conectores e, por isso, as orações enlaçadas se devem considerar justapostas. (BECHARA, 1999, p. 321).

Bechara (1999) evoca as categorias fonte desses elementos e desconsidera o processo de gramaticalização pelo qual esses itens passam. A razão para não incluir esses elementos no rol das conjunções é que alguns correlatores, como seja...seja, ainda possuem características fortemente verbais, como a possibilidade de flexão (sejam...sejam). Essa certamente é uma das razões para o autor considerar justapostas as estruturas ligadas pelos elementos citados.

Carvalho (2011, p. 365) apresenta o correlator seja...seja como conjunção, no entanto, condena o uso da conjunção flexionada (do tipo sejam...sejam). Vejamos:

A conjunção seja, por ser conjunção, é invariável. Está, portanto, corretíssima a seguinte passagem da coluna "coisas de política", de Rosângela Bittar (Jornal do Brasil, 24-12-96): "Portanto ficam sem fundamento as interpretações de recentes declarações do presidente sobre o plebiscito, seja as feitas a deputados (...), seja as expostas em entrevistas (...)". A tendência do usuário da língua seria pôr no plural as duas ocorrências de seja.

Notamos que Carvalho (2011) classifica como um "erro" o uso flexionado da conjunção seja...seja. Isso se deve a uma visão bastante rígida do conceito de conjunção. De fato, em geral, as conjunções são palavras invariáveis, sem possibilidade de flexão. Por outro lado, a invariabilidade desses termos linguísticos, apesar de ser uma característica bastante prototípica, não abarca a totalidade das conjunções de uma língua. O processo de flexão ainda pode estar presente em alguns conectivos, justamente por estarem em processo de mudança, com sua forma final ainda não estabilizada. 
Além da perspectiva apresentada por Neves (2011), também acrescentamos a visão de Pezatti e Longhin-Thomazi (2008, p. 898), que se filiam ao grupo dos linguistas. Segundo as autoras, a disjunção pode ser efetuada por meio da conjunção ou, simples e dupla. A conjunção ou na forma dupla equivale ao que chamamos neste trabalho de correlação disjuntiva.

Devemos acrescentar que esse estudo desenvolvido pelas autoras, por ter como objetivo uma análise do português em uso, é um dos poucos que faz referência à correlação instanciada por seja...ou. Elas afirmam que esses correlatores, diferentemente do que preveem as convenções normativas, apresentam duas conjunções distintas para estabelecer a ligação de prótase e apódose.

\section{Pressupostos teórico-metodológicos}

Para esta pesquisa, foram utilizados os pressupostos teórico-metodológicos da Linguística Funcional Centrada no Uso (LFCU) ou Abordagem Construcional da Gramática (TRAUGOTT, TROUSDALE, 2013; BYBEE, 2015; ROSÁRIO, OLIVEIRA, 2016; CEZÁRIO, FURTADO DA CUNHA, 2013), que representa a união de conceitos da Linguística Funcional de vertente norte-americana com a Linguística Cognitiva.

Observamos que, a partir dessa fusão, a gramática passa a ser concebida como uma representação da experiência dos indivíduos com a língua, considerando, ainda, que há padrões regulares de uso e formas emergentes em convivência. Assim, a estrutura da língua emerge à proporção de seu uso, e a gramática é compreendida como em constante adaptação em consequência do discurso.

Nessa perspectiva teórica, a gramática é vista em sua totalidade, e forma e significado são pareados como iguais, passando a funcionar como unidades básicas e centrais da língua, operando em diferentes níveis. Com isso, a LFCU prevê que todas as unidades da língua são simbólicas - desde morfemas simples, passando por expressões idiomáticas, estruturas sintáticas (GOLDBERG, 1995, 2006), até padrões mais abstratos.

Dentro dessa perspectiva, defendemos que os correlatores disjuntivos são, de fato, construções linguísticas gramaticais, tendo em vista que são dotados de forma e sentido. Ademais, constituem nós na rede dos conectores em língua portuguesa.

À luz desses fundamentos teóricos, foram analisados textos de 61 edições da Revista Veja on-line, disponíveis em http://www.veja.abril.com.br, no período de janeiro de 2013 a fevereiro de 2014. Assim, a pesquisa caracteriza-se 
como sincrônica, com foco no Português do Brasil (PB) escrito, especialmente na variedade linguística utilizada pela mídia escrita.

Na primeira fase da análise, foram coletados todos os correlatores que estabelecem a noção de disjunção, tanto em estruturas oracionais quanto não oracionais. Em seguida, com base na constatação de alguns autores, como Raposo et alii (2013), de que a correlação com ou...ou apresenta uma leitura semântica de exclusão, decidimos observar quais types apresentavam a leitura semântica de exclusão ou inclusão, em um maior refinamento analítico.

\section{Resultados}

Foram encontrados oito diferentes correlatores estabelecendo a correlação disjuntiva. Vejamos esses types, acompanhados de sua frequência de uso (cf. ACOSTA, 2016, p. 54):

Tabela 1: Types de construções correlatas disjuntivas.

\begin{tabular}{|c|c|c|}
\hline Types & Tokens & $\%$ \\
\hline ou...ou & 63 & $34,8 \%$ \\
\hline seja...seja & 42 & $23,2 \%$ \\
\hline seja..ou & 32 & $17,7 \%$ \\
\hline ora..ora & 21 & $11,6 \%$ \\
\hline nem...nem & 16 & $8,8 \%$ \\
\hline quer...quer & 4 & $2,2 \%$ \\
\hline quer..ou & 2 & $1,2 \%$ \\
\hline nem...ou & 1 & $0,5 \%$ \\
\hline Total & $\mathbf{1 8 1}$ & $\mathbf{1 0 0 \%}$ \\
\hline
\end{tabular}

A primeira importante observação acerca da tabela 1 é que a correlação disjuntiva estabelece-se na língua em uso por meio de correlatores espelhados, ou seja, repetidos (ou...ou, seja...seja, ora...ora, nem...nem e quer...quer), ou 
por meio de correlatores não espelhados, ou seja, diferentes (seja...ou, quer... ou e nem...ou). Na seção a seguir, veremos mais detalhadamente cada um dos correlatores espelhados e não espelhados encontrados no corpus.

Ao observarmos a tabela 1, verificamos que o type ou...ou apresenta-se como o mais frequente entre as construções correlatas disjuntivas, como era esperado, já que as gramáticas, de um modo geral, apresentam a conjunção ou como a mais utilizada pelos usuários da língua no campo da alternância.

De acordo com Traugott e Trousdale (2013), construções são objetos linguísticos convencionais cuja frequência de ocorrência pode influenciar a categorização. Sendo assim, calcados na perspectiva construcional, que funciona como aporte teórico para esta pesquisa, concluímos que o type ou...ou é o membro central prototípico das construções correlatas disjuntivas, pois se apresenta como um exemplar de alta frequência dentro de sua categoria e já está altamente convencionalizado pelos usuários da língua. É um correlator econômico (bem leve em termos fonológicos) e facilmente acessível pelos falantes em seu repertório linguístico. Tudo isso corrobora a prototipicidade de ou...ou .

A partir da análise da tabela, verificamos também que, curiosamente, o terceiro type mais frequente de construção correlata foi seja...ou, um correlator que não está previsto nas gramáticas normativas e que é pouco abordado pelas gramáticas em geral, inclusive pelas que apresentam uma visão menos tradicional a respeito dos fenômenos linguísticos. Nas subseções seguintes, com base na perspectiva construcional, apresentaremos uma hipótese para como o type seja...ou foi recrutado pelos falantes da língua portuguesa.

Por ora, destacamos que a observação da alta frequência apresentada pelo type seja...ou demonstra a importância de se levar em conta a língua em uso na análise linguística, e ressalta a necessidade de se fazer uma revisão de nossas obras gramaticais. Afinal, novos padrões precisam ser contemplados, visto que já são atestados, inclusive, em textos normatizados do português padrão, como são os textos midiáticos utilizados no corpus desta pesquisa.

\subsection{Correlatores espelhados}

A análise dos dados revelou cinco types de construções correlatas disjuntivas formadas por correlatores espelhados. Observemos quais são eles, acompanhados de sua frequência de uso: 
Tabela 2: Types de construções correlatas disjuntivas espelhadas

\begin{tabular}{|c|c|c|}
\hline Types & Tokens & $\%$ \\
\hline ou...ou & 63 & $43,1 \%$ \\
\hline seja...seja & 42 & $28,7 \%$ \\
\hline ora...ora & 21 & $14,4 \%$ \\
\hline nem...nem & 16 & $10,9 \%$ \\
\hline quer..quer & 4 & $2,9 \%$ \\
\hline Total & $\mathbf{1 4 6}$ & $\mathbf{1 0 0 \%}$ \\
\hline
\end{tabular}

Atestamos, com base na tabela 2, que os types espelhados são os mais prototípicos, já que das 181 ocorrências encontradas, 146 , ou seja, $80,6 \%$ dos dados são formadas por types dessa natureza.

Esses correlatores espelhados podem ser divididos em três grupos, a partir dos elementos gramaticais que os formam: os de base conjuncional, os de base verbal e os de base substantiva. Vejamos cada grupo em particular.

\subsubsection{Correlatores de base conjuncional}

Os correlatores disjuntivos espelhados ou...ou e nem...nem, encontrados no corpus de análise, originaram-se, por via histórica, das conjunções ou e nem respectivamente. Esses correlatores são tradicionalmente apresentados nas gramáticas, como já dissemos, como conjunções coordenativas.

Rocha Lima (1999) e Cunha e Cintra (2001) apresentam esses elementos apenas como uma repetição das conjunções ou e nem. No entanto, veremos, a seguir, que esses correlatores não são apenas uma repetição das conjunções já existentes, já que apresentam valores semânticos e pragmáticos diferenciados em relação à sua conjunção de origem.

Como era previsto, já que as gramáticas de um modo geral apresentam a conjunção ou como a mais utilizada pelos usuários da língua no plano semântico da alternância, as construções espelhadas com ou...ou confirmaram-se como as correlatas disjuntivas prototípicas em nosso corpus.

Dos 146 tokens, 63 ocorrências (quase 44\% das construções) são encabeçadas por ou...ou, confirmando, assim, sua exemplaridade em relação aos outros correlatores disjuntivos, provavelmente por serem mais curtos, mais 
leves em relação à sua quantidade de massa fônica e pela maior facilidade de processamento em relação aos outros types. Observemos o dado a seguir:

\begin{tabular}{|c|l|l|l|}
\cline { 2 - 4 } \multicolumn{2}{c|}{} & \multicolumn{1}{c|}{ PRÓTASE } & \multicolumn{1}{c|}{ APÓDOSE } \\
\hline \multirow{3}{*}{$(1)$} & $\begin{array}{l}\text { As forças assadistas } \\
\text { parecem estar nos } \\
\text { tomando a dianteira, } \\
\text { deixando a Síria com } \\
\text { duas opções: }\end{array}$ & $\begin{array}{l}\text { ou continua, na maior } \\
\text { parte, sob o domínio } \\
\text { do tirano }\end{array}$ & $\begin{array}{l}\text { ou cai nas mãos dos fundamen- } \\
\text { talistas mulçumanos que hoje } \\
\text { controlam praticamente todas as } \\
\text { forças da rebelião. }\end{array}$ \\
\hline
\end{tabular}

Revista Veja on-line, ed.22/05/2013, p. 29

Nessa ocorrência, observamos que os correlatores ou...ou transmitem à construção uma noção semântica de disjunção exclusiva, já que uma opção exclui a outra. A Síria deve escolher entre uma opção ou outra: ou continua sendo dominada ou cai nas mãos dos fundamentalistas. A interpretação exclusiva fica ainda mais evidenciada pela porção textual que precede a prótase correlativa ("deixando a Síria com duas opções”) (grifo nosso).

A manifestação de uma interpretação exclusiva nas construções com ou... ou foi observada em todas as estruturas encabeçadas por esse par de correlatores, ou seja, os 63 tokens instanciados apresentaram a leitura de exclusão, confirmando a afirmação de Pezatti e Loghin-Thomazi (2008, p. 899) e de outros autores de que a repetição da conjunção ou não indica uma "mera variação estilística ou enfática", mas uma oposição dos sentidos expressos pelas conjunções. Ou seja, o par ou...ou é utilizado no português atual apenas para indicar a exclusão, com uma função distinta do ou coordenativo.

A disjunção exclusiva é apontada como uma particularidade de ou...ou também por outros autores. Neves (2011), por exemplo, afirma que o conectivo $o u$ ora indica inclusão, ora exclusão, destacando, no entanto, que a disjunção com ou...ou sempre será exclusiva. Em relação à frequência de ou e ou...ou, Pezatti e Loghin-Thomazi (2008, p. 900) ressaltam que a forma ambígua ( $A$ ou $B$ ) é a não marcada no português falado no Brasil, ao passo que a forma exclusiva (ou $A$ ou $B$ ) é a forma marcada. Sendo assim, as autoras concluem que ou...ou é menos produtivo, justamente pelo fato de significar apenas exclusão, com menor espectro de uso.

A comprovação de que as construções correlatas disjuntivas com ou... ou veiculam apenas a semântica de exclusão reforça seu estatuto particular, demonstrando que essa construção é diferente de ou simples. Portanto, as cor- 
relatas disjuntivas não podem ser englobadas dentro da coordenação com ou, devido às suas peculiaridades.

Já a partícula nem, de acordo com Barreto (1992, p. 85-86), pode funcionar como um advérbio ou conjunção aditiva negativa correspondendo a $e$ não, $\mathrm{e}$ "vem sempre precedida de sentença negativa". Já o par nem...nem, ainda segundo a autora citada, teria valor correlativo alternativo, no sentido de expressar uma "alternância negada". O par nem...nem já era empregado no latim, antes de itens lexicais, sintagmas ou sentenças.

Vejamos, a seguir, um dos tokens encontrados de nem...nem.

\begin{tabular}{|c|l|c|c|c|}
\cline { 2 - 4 } \multicolumn{2}{c|}{} & PRÓTASE & APÓDOSE & \multicolumn{1}{c|}{} \\
\hline \multirow{3}{*}{$(2)$} & $\begin{array}{l}\text { A paz é um dueto, } \\
\text { não um solo. E não } \\
\text { tivemos ainda uma só } \\
\text { declaração, }\end{array}$ & nem da OLP, & nem do Hamas, & $\begin{array}{l}\text { Muito menos do He- } \\
\text { zbollah, que aceite o } \\
\text { direito de Israel existir. }\end{array}$ \\
\hline
\end{tabular}

Revista Veja on-line, ed.15/01/2014-,pág. 19

Atestamos, no dado (2), que o correlator nem...nem estabelece uma correlação disjuntiva negativa, assim como citado por Barreto (1992). Entretanto, reconhecemos que os limites entre alternância e adição tornam-se altamente difusos, a ponto de ser possível a postulação de uma construção alternativo-aditiva, de cunho negativo.

Segundo Santos (1990, p.72), "o uso de nem em lugar de ou tem como efeito não somente a apresentação de alternativas, mas, mais do que isso, a negação, simultânea à apresentação dessas mesmas alternativas". Ou seja, duas alternativas são apresentadas para mostrar que elas não se realizam.

Observemos outra ocorrência de nem...nem, encontrada nos dados:

\begin{tabular}{|l|l|l|l|}
\cline { 3 - 4 } \multicolumn{2}{c|}{} & \multicolumn{1}{c|}{ PRÓTASE } & \multicolumn{1}{c|}{ APÓDOSE } \\
\hline \multirow{2}{*}{$(3)$} & $\begin{array}{l}\text { Mas sua desgraça é que } \\
\text { não cresceu, }\end{array}$ & $\begin{array}{l}\text { nem perto do neces- } \\
\text { sário, }\end{array}$ & $\begin{array}{l}\text { nem com a rapidez de que } \\
\text { precisava. }\end{array}$ \\
\hline
\end{tabular}

Revista Veja on-line, ed. 25/12/2013, pág. 60

Observamos, no token citado, que o correlator nem...nem estabelece a disjunção negativa entre prótase e apódose, apresentando alternativas que não 
se realizaram, assim como afirmado anteriormente por Santos (1990). Essa interpretação é reforçada pela presença da partícula não, que antecede a prótase. De fato, todo contexto reforça a polaridade negativa do discurso.

Verificamos, ainda, em relação ao valor semântico de nem...nem, que todas as construções, diferentemente de ou...ou, apresentaram a leitura semântica de inclusão, com uma especificidade já levantada: uma inclusão de cunho negativo, o que reforça o caráter híbrido dessa construção, visto que compartilha traços com a noção de adição. Vejamos:

\begin{tabular}{|l|l|c|c|}
\cline { 2 - 3 } \multicolumn{2}{c|}{} & PRÓTASE & APÓDOSE \\
\hline \multirow{4}{*}{ (4) } & $\begin{array}{l}\text { O desprezo pela canção popular - ou } \\
\text { popularesca, como preferem alguns - tem } \\
\text { certo preconceito de classes. Em geral, } \\
\text { seus intérpretes são de origem humilde e } \\
\text { têm pouca escolaridade. Musicalmente o } \\
\text { brega não cultiva }\end{array}$ & nem a tradição & nem a modernidade \\
\hline
\end{tabular}

Revista Veja on-line, ed. 01/01/2014, pág. 90

Observamos, no token citado, que a música brega não cultiva a tradição e também não cultiva a modernidade, ou seja, não cultiva nenhuma das duas. Sendo assim, a leitura apresentada é de inclusão.

\subsubsection{Correlatores de base verbal}

Os correlatores espelhados seja...seja e quer...quer são de base verbal, pois tiveram como origem os verbos ser e querer, respectivamente. Esses correlatores, assim como os já citados, também apresentaram um traço persistente de sua palavra de origem: preservaram características verbais que atuam no comportamento sintático e semântico dessas construções, como veremos a seguir.

O primeiro type espelhado de base verbal a ser analisado é o seja...seja. Esse type aparece em segundo lugar na preferência dos usuários da língua, no corpus analisado. Dos 146 types espelhados apresentados na análise de dados, 42 tokens são de seja...seja.

O correlator seja...seja, de acordo com Pezzatti e Longhin-Thomazi (2008, p. 898), "manifesta, na realidade, uma forma de repetição do predicado verbal, que parece estar se gramaticalizando como conjunção". Sendo assim, as autoras afirmam que a conjunção ainda se encontra em processo de mudança. Vejamos um dos tokens encontrados em nossos dados: 


\begin{tabular}{|c|l|l|l|l|}
\cline { 3 - 4 } \multicolumn{2}{c|}{} & \multicolumn{1}{c|}{ PRÓTASE } & \multicolumn{1}{c|}{ APÓDASE } & \multicolumn{1}{c}{} \\
\multirow{2}{*}{$(5)$} & $\begin{array}{l}\text { O direito } \\
\text { de ir e vir é } \\
\text { sagrado, }\end{array}$ & $\begin{array}{l}\text { seja para } \\
\text { pobre, }\end{array}$ & seja para rico, & $\begin{array}{l}\text { inclusive nos shoppings. Mas } \\
\text { precisa ir em bando de 500, } \\
1000,2000 ?\end{array}$ \\
\hline
\end{tabular}

Revista Veja on-line, ed. 29/01/2014, pág. 27.

Em (5), observamos que o type seja...seja estabelece a correlação disjuntiva entre dois termos, ou seja, correlaciona estruturas não oracionais e apresenta a alternância típica da construção disjuntiva. O fato de seja...seja correlacionar, com maior frequência, termos não oracionais (cf. ACOSTA, 2016) configura, em nossa pesquisa, uma característica particular desse correlator.

A preferência de seja...seja pelas construções não oracionais é uma constatação de que o correlator, por si só, ainda preserva características de seu estatuto verbal. De fato, dos 42 tokens instanciados, 32 correlacionavam termos não oracionais.

Alguns autores tecem comentários sobre os resquícios verbais preservados por seja...seja. Por exemplo, Camacho (1999, p. 2687), ao analisar a língua espanhola, ressalta a distribuição sintática diferenciada apresentada por esse correlator em relação aos outros types disjuntivos. O autor afirma que seja... seja coordena orações e sintagmas preposicionados, mas sua distribuição é bem mais limitada com argumentos do verbo. Sendo assim, apresenta a preferência por sintagmas preposicionados. É o que constatamos em nossos dados, visto que, das 32 construções de seja...seja não oracionais encontradas, 19 eram compostas por sintagmas preposicionados.

O autor salienta, ainda, que, por preservar o seu caráter verbal, o correlator seja...seja bloqueia a proximidade de outros verbos, e daí a sua preferência por correlacionar termos não oracionais. Um fator ainda mais saliente desse resquício verbal é o aparecimento, em alguns dados, do seja flexionado. Vejamos o token a seguir:

\begin{tabular}{|c|l|l|l|}
\cline { 3 - 4 } \multicolumn{2}{c|}{} & \multicolumn{1}{c|}{ PRÓTASE } & \multicolumn{1}{c|}{ APÓDASE } \\
\hline \multirow{4}{*}{$(6)$} & $\begin{array}{l}\text { Suíços fazem ótimos cho- } \\
\text { colates, fabricam esplêndi- } \\
\text { dos relógios e, alpinos que } \\
\text { são adoram montanhas. }\end{array}$ & $\begin{array}{l}\text { sejam aquelas de cumes } \\
\text { gelados, }\end{array}$ & $\begin{array}{l}\text { sejam as nem tão meta- } \\
\text { fóricas assim, compos- } \\
\text { tas de euros e dólares } \\
\text { convertidos em francos } \\
\text { nativos. }\end{array}$ \\
\hline
\end{tabular}

Revista Veja on-line, ed. 15/05/2013, pág. 102 
Em (6), o seja...seja aparece flexionado (sejam... sejam), apresentando mais um indício de que o correlator ainda preserva traços verbais, já que as conjunções tradicionalmente, por definição, não recebem o traço da flexão.

A seguir, observamos outro token, apresentando o correlator sejam...seja, ainda mais idiossincrático. Observemos:

\begin{tabular}{|c|l|l|l|}
\cline { 3 - 4 } \multicolumn{2}{c|}{} & \multicolumn{1}{c|}{ PRÓTASE } & \multicolumn{1}{c|}{ APÓDASE } \\
\hline (7) & $\begin{array}{l}\text { Prada tem um quarto só seu, } \\
\text { decorado com borboletas na } \\
\text { parede, e adora enfeites }\end{array}$ & $\begin{array}{l}\text { sejam as bijuterias da } \\
\text { dona, }\end{array}$ & $\begin{array}{l}\text { seja sua própria } \\
\text { gargantilha de pérolas } \\
\text { verdadeiras. }\end{array}$ \\
\hline
\end{tabular}

Revista Veja on-line, ed. 14/08/2013, pág. 97

Nesse token, constatamos que apenas o primeiro correlator é flexionado, pois acompanha a marca de plural do sintagma nominal presente na prótase (as bijuterias da dona). O segundo correlator mantém-se em uma forma não marcada, justamente por combinar-se com um sintagma singular (sua própria gargantilha de pérolas verdadeiras).

A análise dos dados de seja...seja revelou também que, em todas as ocorrências, a disjunção apresentada é inclusiva. Vejamos:

\begin{tabular}{|c|l|l|l|}
\hline & & \multicolumn{1}{|c|}{ PRÓTASE } & \multicolumn{1}{c|}{ APÓDASE } \\
\hline (8) & $\begin{array}{l}\text { Os autômatos tomam } \\
\text { suas próprias decisões }\end{array}$ & $\begin{array}{l}\text { seja em situações de } \\
\text { policiamento }\end{array}$ & $\begin{array}{l}\text { seja em zonas de intervenção } \\
\text { militar. }\end{array}$ \\
\hline
\end{tabular}

Revista Veja on-line, ed. 05/02/2014, pág. 103

Verificamos que os autômatos tomam suas próprias decisões tanto em situações de policiamento quanto em zonas de intervenção militar. Há, portanto, uma ideia de inclusão, e não exclusão, como comumente ocorre com o correlator ou...ou. Sendo assim, a disjunção com seja...seja é tipicamente inclusiva.

O segundo correlator de base verbal encontrado nos dados foi quer...quer. De acordo com Barreto (1999, p. 450), a conjunção quer é derivada do verbo querer de $3^{\mathrm{a}}$ pessoa do presente do indicativo que, por sua vez, é "oriundo do latim quaerere, 'buscar', 'aspirar', 'desejar'”. Ainda segundo a autora, a conjunção correlativa quer...quer originou-se a partir de um processo de recategorização (verbo > conjunção) e foi acompanhada, em alguns casos, por uma mudança de conteúdo semântico, pois pode indicar, em alguns contextos, um valor concessivo-condicional como observado no exemplo seguinte, tam- 
bém fornecido por Barreto (1999): Quer eu faça isto, quer eu faça aquilo, ela sempre reclama comigo.

No exemplo citado, a autora demonstra que poderíamos facilmente substituir a conjunção duplicada quer pela conjunção condicional se. Outros autores como Garcia (1975) também ressaltaram o caráter concessivo-condicional de quer..quer, no entanto, a autora ressalta que, em outros casos, a conjunção apresenta seu valor primitivo, o alternativo, e segue o valor semântico de ou... ou, como no exemplo a seguir: Quer chova quer faça sol, irei à praia.

Em nossos dados, foram encontrados apenas quatro tokens de quer...quer, demonstrando ser este o correlator menos frequente entre os que veiculam a noção de disjunção. Vejamos a seguir um desses tokens encontrados:

\begin{tabular}{|c|l|c|c|}
\cline { 3 - 4 } \multicolumn{2}{c|}{} & PRÓTASE & APÓDOSE \\
\hline \multirow{3}{*}{$(9) \quad \begin{array}{l}\text { Não importa o destino do projeto de lei, } \\
\text { é evidente que prostitutas, por necessida- } \\
\text { de, gosto ou as duas coisas, continuarão } \\
\text { a vender seus serviços, }\end{array}$} & quer você queira, & quer não. \\
\hline
\end{tabular}

Revista Veja on-line, ed.19/02/2014, pág. 23

Verificamos também que, apesar de o correlator quer...quer apresentar uma base verbal como seja...seja, em nenhum caso admite a flexão. De acordo com Kury (2003), isso ocorre porque, diferentemente do que acontece com seja... seja, a conjunção quer.quer já está totalmente gramaticalizada, permanecendo, assim, sempre invariável. Observamos que, em todos os tokens instanciados pelo type quer...quer, a disjunção apresentada foi também inclusiva, assim como aconteceu com o type seja...seja.

\subsubsection{Correlatores de base substantiva}

Um dos correlatores encontrados, em nossa análise, apresenta como base uma palavra substantiva. É o caso do correlator ora...ora.

Barreto (1999) afirma que o substantivo latino hora, precedido do demonstrativo hac (hac hora) deu origem ao advérbio português agora 'nesta hora', 'neste momento'. Já a preposição ad (ad hora) mais o substantivo hora deu origem ao advérbio português ora, semanticamente equivalente.

O type ora...ora também apareceu nos dados como um dos correlatores que instanciam construções correlatas disjuntivas, totalizando 21 tokens. Observemos um dado: 


\begin{tabular}{|c|l|l|l|}
\cline { 3 - 4 } \multicolumn{1}{c|}{} & \multicolumn{1}{c|}{ PRÓTASE } & \multicolumn{1}{c|}{ APÓDOSE } \\
\hline \multirow{4}{*}{$(10)$} & $\begin{array}{l}\text { O cantor carioca, nascido } \\
\text { João Luiz Wordenberg } \\
\text { Filho, passou boa parte } \\
\text { da vida trombando }\end{array}$ & $\begin{array}{l}\text { ora com a lei (nos anos } 80, \\
\text { usuário contumaz de dro- } \\
\text { gas diversas, era chamado } \\
\text { tantas vezes às delegacia } \\
\text { que passou a andar com } \\
\text { algemas no bolso) }\end{array}$ & $\begin{array}{l}\text { ora com seus colegas } \\
\text { músicos. }\end{array}$ \\
\end{tabular}

Revista Veja on-line, ed. 28/08/2013, pág. 15

Em (10), percebemos que o correlator ora...ora, além da disjunção, também veicula um valor temporal secundário que pode ser percebido com clareza. Observamos que prótase e apódose poderiam ser parafraseadas por: "O músico, em alguns momentos, tinha problemas com a polícia e, em outros momentos, com seus colegas".

A semântica temporal apresentada por esse correlator pode ser depreendida por conta da persistência de sua palavra de origem, como foi explicado por Barreto (1999), em uma visão essencialmente diacrônica. Em todos os tokens encontrados, o correlator ora...ora, de fato, preserva o conteúdo semântico de tempo. Observemos o dado a seguir:

\begin{tabular}{|c|l|c|l|}
\cline { 3 - 4 } \multicolumn{2}{c|}{} & \multicolumn{1}{c|}{ PRÓTASE } & \multicolumn{1}{c|}{ APÓDOSE } \\
\hline \multirow{2}{*}{$(11)$} & $\begin{array}{l}\text { Vivemos a era do individualismo tecno- } \\
\text { lógico. Criamos perfis virtuais que nem } \\
\text { sempre condizem com a realidade. Com } \\
\text { alguns cliques, }\end{array}$ & $\begin{array}{l}\text { ora nos apre- } \\
\text { sentamos como } \\
\text { pessoas amáveis, }\end{array}$ & $\begin{array}{l}\text { ora como pessoas } \\
\text { totalmente pode- } \\
\text { rosas. }\end{array}$ \\
\hline
\end{tabular}

Revista Veja on-line, ed. 16/01/2013, pág. 28

Percebemos que a noção semântica de tempo também é facilmente percebida no token acima. Com relação aos perfis criados nas redes virtuais, verificamos que, em alguns momentos, "nos apresentamos como pessoas amáveis" e, em outros momentos, "como pessoas totalmente poderosas". Verificamos, também, que todos os tokens instanciados pelo type ora...ora apresentam a leitura semântica de exclusão. Observemos mais um dado: 


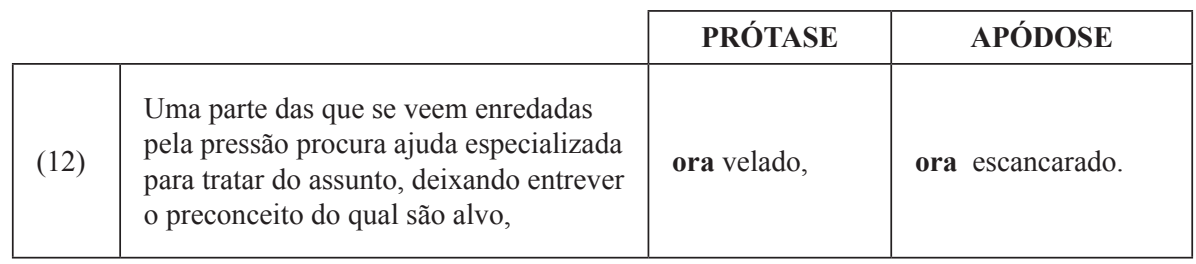

Revista Veja on-line, ed. 29/05/2013, pág. 120

Notamos que, em (12), um momento exclui o outro. Em alguns momentos, o preconceito é velado, em outros momentos ele é escancarado. É impossível, portanto, uma leitura inclusiva.

\subsection{Correlatores não espelhados}

A análise dos dados revelou três types da construção correlata disjuntiva não espelhada, ou seja, formada por correlatores com itens diferenciados. Vejamos:

Tabela 3 - Types de construções correlatas disjuntivas não espelhadas

\begin{tabular}{|c|c|c|}
\hline Types & Tokens & \% \\
\hline seja..ou & 32 & $91,44 \%$ \\
\hline quer..ou & 2 & $5,71 \%$ \\
\hline neт...ou & 1 & $2,85 \%$ \\
\hline Total & 35 & $\mathbf{1 0 0 \%}$ \\
\hline
\end{tabular}

Foram encontradas 32 ocorrências do type seja...ou na análise dos dados, o que é uma frequência alta para um correlator disjuntivo considerado não canônico, tendo em vista que as gramáticas, de um modo geral, não mencionam a existência desse conector. Ademais, devemos frisar que essas ocorrências foram flagradas em um corpus com forte apelo normativista, como é a Revista Veja.

Pezzati e Loghin-Thomazi (2008) enquadram o correlator seja...ou dentro dos disjuntores, e afirmam que a associação de seja com ou é frequentemente licenciada na língua em uso. Vejamos, para fins ilustrativos, um dado de cada token não espelhado encontrado no corpus: 


\begin{tabular}{|c|l|c|c|}
\cline { 3 - 4 } \multicolumn{2}{c|}{} & PRÓTASE & APÓDOSE \\
\hline \multirow{2}{*}{$(13)$} & $\begin{array}{l}\text { Além disso, o aumento na } \\
\text { capacidade portuária depen- } \\
\text { de de avanços no acesso aos } \\
\text { terminais, }\end{array}$ & seja por rodovias, & ou ferrovias. \\
\hline
\end{tabular}

Revista Veja on-line, ed. 22/05/2013, pág. 120

\begin{tabular}{|c|l|c|c|}
\cline { 3 - 4 } \multicolumn{2}{c|}{} & \multicolumn{1}{c|}{ PRÓTASE } & \multicolumn{1}{c|}{ APÓDOSE } \\
\hline \multirow{3}{*}{$(14)$} & $\begin{array}{l}\text { "Niels por que a ferradura? } \\
\text { Você não pode acreditar } \\
\text { nisso". Ele respondeu: É claro } \\
\text { que não acredito . Mas isso } \\
\text { funciona }\end{array}$ & quer você acredite & ou não. \\
\hline
\end{tabular}

Revista Veja on-line, ed. 15/01/2014, pág. 19

\begin{tabular}{|c|l|l|l|}
\cline { 3 - 4 } \multicolumn{2}{c|}{} & PRÓTASE & APÓDOSE \\
\hline \multirow{2}{*}{$(15)$} & $\begin{array}{l}\text { Ninguém faz nada quanto a isso; por alguma } \\
\text { razão misteriosa, insondável, nada se corrige. } \\
\begin{array}{l}\text { Homens, mulheres, jogados aos magotes em } \\
\text { celas que não admitiriam razoavelmente }\end{array}\end{array}$ & nem seis, & ou dez. \\
\hline
\end{tabular}

Revista Veja on-line, ed. 18/12/2013, pág. 32

Observamos que todos os tokens instanciados pelos types quer...ou, seja... ou e nem...ou apresentam a leitura semântica de inclusão. Outro traço geral é que todos são formados a partir da mescla de types espelhados já existentes.

Para explicarmos o surgimento dessas formas, valemo-nos da obra de Traugott e Trousdale (2013). Segundo esses autores, um dos mecanismos de mudança existentes para explicar o surgimento de uma nova construção é o fenômeno da analogização. Na analogização, o falante reconfigura e alinha traços de uma construção já existente para a formação de uma construção nova (cf. ROSÁRIO, 2017).

O exemplar da categoria de uma construção é tomado como um modelo para a criação de novos types. Sendo assim, observamos que o mecanismo da analogização é útil para a interpretação dos mecanismos de mudança operados na criação dos types seja...ou, quer ...ou e nem...ou. 
Esses types foram formados, de fato, por meio da atração de membros e de construtos já existentes, que são os seguintes: seja...seja, quer...quer, nem... nem e ou...ou. Os correlatores não espelhados alinham traços das velhas e das novas construções, possibilitando a emergência de novas formas. Vejamos a figura abaixo (cf. ACOSTA, 2016, p. 86):

Figura 1: Efeito da analogização nas construções não espelhadas

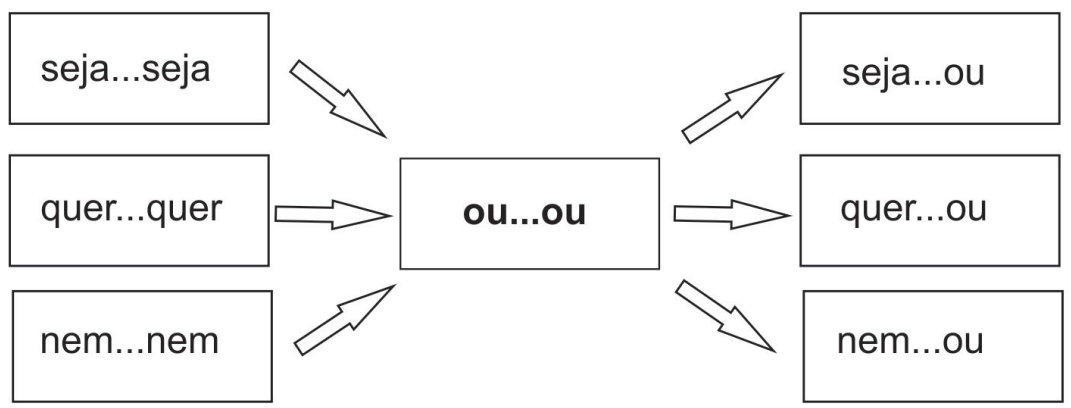

Observamos, a partir da figura 1, que o type ou...ou está parcialmente presente em todos os novos types criados, demonstrando grande produtividade. Isso ocorre por ser ele o membro exemplar da categoria das construções correlatas disjuntivas, o que pode ser comprovado pela sua antiguidade e alta frequência token até os dias de hoje. De fato, o conectivo ou é o elemento alternativo/ disjuntivo por excelência. Daí a presença dele nos novos types formados, garantindo a persistência desse matiz semântico fundamental.

De acordo com a abordagem construcional proposta por Traugott e Trousdale (2013), esse fenômeno acontece porque, ao utilizarmos a língua, acessamos informações estocadas, e aquelas que são mais frequentes são acessadas com maior facilidade. Sendo assim, como o type ou...ou é o mais frequente, ele é mais facilmente recrutado pelo usuário da língua.

Bybee (2015), em estudo recente, acrescenta que formas com alta frequência são resistentes à mudança e mais suscetíveis a servirem como base para inovações linguísticas, assim como ocorre com as construções com ou...ou aqui citadas. De fato, por serem mais fortemente representadas na memória, são mais facilmente acessadas e utilizadas como base para a criação dos novos usos.

Bybee (2015) enriquece os estudos de mudança linguística ao propor os conceitos de nivelamento analógico e extensão. O primeiro ocorre quando uma 
nova forma criada a partir da base de um paradigma elimina uma alternativa mais antiga já existente. Já a extensão, ocorre quando há um acréscimo no paradigma, baseado em um modelo prototípico.

Com base nesses postulados, é possível hipotetizarmos que o processo de mudança que deu origem aos pares correlatos não espelhados é o da extensão, já que observamos, a partir deste estudo, uma alternância no paradigma que não elimina formas anteriores. Essa é uma hipótese forte, mas que naturalmente precisará se fundamentar em estudos futuros, com base em dados diacrônicos.

De uma forma geral, com relação aos usos dos correlatores não espelhados, concluímos que os types seja...ou, quer ...ou e nem...ou apresentam-se como marginais na categoria das construções correlatas disjuntivas. Diferentemente do type prototípico ou...ou, que apresenta valor de exclusão, maior possibilidade de inversão e preferência por estruturas oracionais, esses types não espelhados apresentam a leitura semântica de inclusão, menor possibilidade de inversão e apresentam-se com maior frequência em estruturas não oracionais.

Concluímos também que o processo de analogização, ao qual foram submetidos os types para a criação das novas formas, resultou em um processo de mudança que alargou a rede construcional da disjunção correlativa em língua portuguesa (cf. ACOSTA, 2016; ROSÁRIO, 2017).

\section{Considerações finais}

Verificamos, neste trabalho, que a construção correlata disjuntiva pode se apresentar na língua em uso a partir de diversos types, que são dotados de especificidades. Embora tivéssemos inicialmente como referência o type ou... $o u$, que de fato se comprovou como o mais prototípico, e alguns outros mais recorrentes como ora..ora e seja..seja, verificamos a ocorrência de outros correlatores disjuntivos que também estabelecem a disjunção, de forma provavelmente inovadora.

A partir dessa observação em relação aos types, surge um questionamento: Com que finalidade o falante recruta tantos types diferentes para estabelecer a correlação disjuntiva? Concluímos que o falante recruta novas formas, pois seu objetivo é sempre a necessidade de conferir maior expressividade ao discurso, daí a renovação no rol desses conectivos.

Em seguida, a partir da análise minuciosa de cada type, verificamos que, apesar de todos estabelecerem a disjunção, cada correlator apresenta um matiz semântico particular que se encaixa melhor em um determinado contexto de 
uso. Observamos que esse matiz semântico particular apresentado por cada type é decorrente, pelo menos parcialmente, da origem de cada correlator. Vejamos o quadro a seguir, com os correlatores disjuntivos espelhados:

Quadro 2: Contexto de uso das construções correlatas disjuntivas espelhadas. Fonte: Os autores

\begin{tabular}{|c|l|}
\hline Types & \multicolumn{1}{c|}{ Contexto de uso } \\
\hline ou...ou & Exclusão/alternância prototípica. \\
\hline seja...seja & Inclusão/alternativas que não se excluem em padrões não oracionais. \\
\hline ora...ora & Exclusão/estruturas com noção temporal. \\
\hline quer...quer & Inclusão/ alternativas que não se excluem em padrões não oracionais. \\
\hline nem...nem & Negação de duas alternativas. \\
\hline
\end{tabular}

A partir do quadro 2, observamos que o type ou...ou é recrutado pelo falante para explicitar a alternância prototípica, em que se apresentam alternativas com o valor preciso de exclusão.

Já o type seja...seja é recrutado nos casos em que o falante quer explicitar duas alternativas que não se excluem, representando, na verdade, um acréscimo, uma inclusão de alternativas, por meio de padrões não oracionais.

O type ora...ora também é indicado para expressar exclusão, no entanto, a sua noção semântica temporal faz com que ele seja recrutado para as estruturas em que o falante deseja veicular, mesmo que subsidiariamente, uma noção de tempo.

Já o type quer...quer parece indicar inclusão como seja...seja, entretanto, não podemos tecer afirmações categóricas sobre esse type pelo fato de termos encontrados apenas quatro tokens. Os poucos dados apontam que esse type é mais utilizado para os casos de estruturas oracionais, pelo fato de já estar totalmente gramaticalizado e não bloquear a presença dos verbos como ocorre com seja...seja.

O type nem...nem é recrutado pelo usuário da língua quando o falante quer apresentar uma negação das alternativas apresentadas, sendo bastante próximo da noção de adição, o que poderia até mesmo possibilitar uma classificação do tipo alternativo-aditivo.

Já com relação aos types não espelhados, embora tenhamos percebido que tenham trazido traços de seus correlatores de origem, não foi possível depreender nesta pesquisa os contextos exatos de seus usos. Essa é uma questão aparentemente nova, que demandará mais estudos em vista de um maior aprofundamento futuro. 
Enfim, ao concluirmos este artigo, cumprimos o intento de apresentar o inventário atualizado dos correlatores disjuntivos no português do Brasil, a partir de amostras da variedade culta da mídia escrita. Que outras pesquisas nesse amplo universo da correlação possam se unir a este trabalho, tendo em vista a necessária descrição cada vez mais pormenorizada dessas construções tão preteridas pela Tradição em geral, inclusive abarcando outros corpora representativos de outras variedades e modalidades da língua portuguesa.

\section{Referências bibliográficas}

ACOSTA, Jovana Mauricio. Análise funcional das construções correlatas alternativas. Dissertação (Mestrado em Estudos de Linguagem). UFF, Instituto de Letras, Niterói, 2016.

BARRETO, Therezinha Maria Mello. Gramaticalização das conjunções na história do português. 2v. Tese (doutorado) - Universidade Federal da Bahia, Salvador, 1999.

BECHARA, Evanildo. Moderna Gramática Portuguesa. Rio de Janeiro: Lucerna, 1999.

BYBEE, Joan. The study of language change. In: . Language change. United Kingdom: Cambridge University Press, 2015.

CAMACHO, José. La coordinación. In: BOSQUE, Ignacio; DEMONTE, Violeta. (Orgs.). Gramática Descriptiva de la Lengua Española. Madrid: Espasa, 1999.

CARVALHO, José Augusto. Gramática Superior da Língua Portuguesa. Brasília: Thessaurus, 2011.

CEZARIO, Maria Maura; FURTADO DA CUNHA, Maria Angélica. (Orgs.) Linguística Centrada no Uso: uma homenagem a Mário Martelotta. Rio de Janeiro: Mauad x FAPERJ. 2013.

CUNHA, Celso; CINTRA, Lindley. Nova Gramática do Português Contemporâneo. $3^{\mathrm{a}}$ ed. Rio de Janeiro: Nova Fronteira, 2001.

GARCIA, Othon Moacir. Comunicação em prosa moderna. 3. ed. Rio de Janeiro: FGV, 1975.

GOLDBERG, A. Constructions: a construction approach to argument structure. Chicago:The University of Chicago Press, 1995.

GOLDBERG, A. Constructions at work: the nature of generalization in language. Oxford: Oxford University Press, 2006

KURY, Adriano da Gama. Novas lições de análise sintática. São Paulo: Ática, 2003. 
NEVES, Maria Helena de Moura. Gramática de usos do Português. São Paulo: UNESP, 2011.

PEZATTI, Erotilde Goreti; LONGUIN-THOMAZI, Sanderléia Roberta. As construções coordenadas. In: ILARI, Rodolfo; NEVES, Maria Helena de Moura (Orgs.) Gramática do Português Culto Falado no Brasil: vol. 2 classes de palavras e processos de construção. Campinas, SP: Editora da UNICAMP, 2008.

RAPOSO, Eduardo Buzaglo Paiva et al. (Org.). Gramática do Português. Vol. I e II. Lisboa: Calouste Gulbenkian, 2013.

ROCHA LIMA, Carlos Henrique. Gramática Normativa da Lingua Portuguesa. Rio de Janeiro: José Olympio, 1999.

ROSÁRIO, Ivo da Costa do. Construções correlatas aditivas em perspectiva funcional. 2012. Tese (Doutorado em Estudos da Linguagem). UFF, Instituto de Letras, Niterói, 2012.

ROSÁRIO, Ivo da Costa do. Construções correlatas aditivas na perspectiva da Linguística Funcional Centrada no Uso. In: Anais do IV Seminário Internacional do Grupo de Estudos Discurso \& Gramática e XVII Seminário Nacional do Grupo de Estudos Discurso \& Gramática: Teoria da gramaticalização e Gramática de construções. Natal - RN: Editora da UFRN, 2013. p. 26-41. Disponível em https://degnatal.files.wordpress.com/2015/04/teoria-da-gramaticalizac3a7c3a3o-e-gramc3a1tica-de-construc3a7c3b5es.pdf

ROSÁRIO, Ivo da Costa do. Correlação. In: VIANNA, Edila; DIAS, Nilza Barrozo. (Orgs.). Português III. $1^{\mathrm{a}}$ ed. Rio de Janeiro: Fundação CECIERJ, 2014, v. 1, p. 109-124.

ROSÁRIO, Ivo da Costa do. Sintaxe Funcional. In: OTHERO, Gabriel de Ávila; KENEDY, Eduardo. (orgs.). Sintaxe, Sintaxes: uma introdução. São Paulo: Contexto, 2015, p. 143-162.

ROSÁRIO, Ivo da Costa do. Construções correlatas aditivas e disjuntivas. In: Odisséia, v. Especial, p. 103-124, 2017. Disponível em https://periodicos. ufrn.br/odisseia/article/view/12903/9020.

ROSÁRIO, Ivo da Costa do; OLIVEIRA, Mariangela Rios. Funcionalismo e abordagem construcional da gramática. In: Alfa: Revista de Linguística (UNESP. Online), v. 60, p. 233-259, 2016. Disponível em http://www.scielo. br/pdf/alfa/v60n2/1981-5794-alfa-60 -2-0233.pdf

SANTOS, Liliane Moreira. Nem: negação/adição/argumentação. Dissertação (Mestrado em Linguística). UNICAMP, Campinas, 1990. 
TRAUGOTT, Elizabeth Closs; TROUSDALE, Graeme. Constructionalization and Constructional Changes. Oxford: Oxford University Press, 2013.

Recebido em 22 de janeiro de 2018.

Aceito em 7 de março de 2018. 